\title{
CRESCIMENTO IN VITRO DA ALGA CEPHALEUROS VIRESCENS EM DIFERENTES MEIOS DE CULTURA E SOB EFEITO DE HORMÔNIOS
}

\author{
In vitro growth of the algae Cephaleuros virescens under different culture media and under hormones effect
}

Luana Martins Pires ${ }^{1}$; Marina Gabriela Marques²; Thiago Alves Santos de Oliveira ${ }^{3}$; Elizabeth Amélia Alves Duarte; Daniel Diego Costa Carvalho5*.

\footnotetext{
${ }^{1}$ Mestranda em Proteção de Plantas; Instituto Federal Goiano; luanna_martinspires@hotmail.com

2 Mestranda em Produção Vegetal; Universidade Estadual de Goiás; magabimarques@hotmail.com ${ }^{3}$ Engenheiro Agrônomo, Ph.D; Faculdade Maria Milza; oliveira.tas@gmail.com ${ }^{4}$ Bióloga, Ph.D; Universidade Federal do Recôncavo da Bahia; elizabethaad@gmail.com ${ }^{5}$ Engenheiro Agrônomo, Ph.D; Universidade Estadual de Goiás; *daniel.carvalho@ueg.br *Autor pra correspondência
}

Artigo enviado em 18/05/2017, aceito em 04/01/2018 e publicado em 10/04/2018.

Resumo - A falha frequente na obtenção de um bom rendimento nos cultivos de algas parasitas de plantas em meio de cultura pode ser devido a um conhecimento limitado das necessidades nutricionais desse microrganismo. Objetivou-se neste trabalho avaliar o crescimento in vitro de Cephaleuros virescens em diferentes meios de cultura e sob o efeito de hormônios. Para tanto, discos de ágar contendo micélio do isolado H-27-01 de C. virescens mantidos em meio básico de Bold (MBB) foram repicados para os meios: MBB, meio extrato da folha do hospedeiro agarizado $(\mathrm{EFH})$, Meio Bristol e meio Trebouxia, com e sem adição de hormônios (AIA) e $\left(\mathrm{GA}_{3}\right)$. Em seguida as placas foram mantidas a $25^{\circ} \mathrm{C}$ e fotoperíodo de $12 \mathrm{~h}$, onde foram tomadas as medidas de diâmetro das colônias do $1^{\circ}$ ao $4^{\circ}$ dia para se fazer o cálculo da área abaixo da curva de crescimento micelial (AACCM). O meio de cultura que proporcionou maior crescimento micelial foi o meio Trebouxia, independente do uso de hormônio. O meio MBB apresentou pior desempenho nas avaliações. O meio EFH foi o único meio que apresentou aumento de AACCM quando da adição de hormônios.

Palavras-chave - Mancha de algas. Fruticultura. Fisiologia de algas.

Abstract - The frequent failure to obtain a good mycelium yield in the growth of plant parasitic green algae when in culture medium is caused by an limited knowledge about the nutritional requirement of this microorganism. The aim of this study was to evaluate the in vitro growth of Cephaleuros viressens in different culture media and under the hormone effect. To this end, agar plates containing mycelium of the C. virescens isolate H-27-01 maintained in Bold basic medium (MBB) were mapped to the media: MBB, agarose host leaf extract medium (EFH), Bristol medium and Trebouxia, with and without hormones (AIA) and (GA3). After the plates were maintained at $25^{\circ} \mathrm{C}$ and photoperiod of $12 \mathrm{~h}$, where the measurements of colonies diameter from the 1st to the 4th day were taken to calculate the area below the mycelial growth curve (ABMGC). The culture medium that provided the greatest mycelial growth was the Trebouxia medium, independent of the use of hormone. MBB medium presented worse performance in the evaluations. The EFH medium was the only medium that presented increased AACCM when added hormones.

Key words - Algal leaf spot. Fruticulture. Algal physiology. 


\section{INTRODUÇÃO}

O Brasil é o terceiro maior produtor de frutas no mundo, com uma extensão territorial de 8,5 milhões de quilômetros quadrados de área plantada (Anuário Brasileiro de Fruticultura 2015). Em 2014 as exportações de manga (Mangifera indica L.) foram R\$ 396 milhões e, de janeiro a novembro/15, R \$ 604 milhões (Hortifruit Brasil 2016). Porém, são muitos os problemas encontrados na cadeia produtiva desta cultura, que em muitos casos são limitantes a sua exploração comercial tendo em vista as perdas qualitativas e quantitativas, como as doenças causadas por microrganismos (Sales Júnior et al. 2004, Maia et al. 2011).

Em se tratando desses organismos, pode-se citar as algas Cephaleuros virescens, principalmente por ser amplamente distribuída em regiões tropicais e subtropicais do mundo (Nelson 2008, Gokhale \& Shaikh 2012). Segundo Malagi et al. (2011), no Brasil a mancha de alga já teve incidência relatada nas culturas frutíferas, tais como o abacate, acerola, caju, goiaba, citros e manga. A alga causa danos consideráveis quando sob condições de umidade e temperatura elevadas, preferencialmente em ambientes que possibilitam a manutenção de filme de água na superfície das folhas, o que é necessário para a sua mobilidade e seu desenvolvimento (Poltronieril et al. 2013, Vasconcelos et al. 2016 b). Os sintomas causados pela alga são manchas circulares de coloração alaranjada e textura semelhante a feltro, com o tempo, tendem a se expandir, apresentando coloração pardoacinzentada e superfície lisa, ocupando um grande volume foliar (Ponmurugan et al., 2009; Han et al., 2011).

A falha frequente na obtenção de um bom rendimento nos cultivos de algas parasitas de plantas em meio de cultura pode ser devido a um conhecimento limitado das necessidades nutricionais desse organismo, visto que meios contendo carbono e nitrato ou até hormônios são os mais apropriados para o crescimento das algas (Ponmurugan et al. 2010, Suto \& Ohtani 2011, Sunpapao \& Pitaloka 2015). Para exemplificar a importância deste tópico, pode-se citar o trabalho de Malagi et al. (2011), os quais não obtiveram sucesso na multiplicação da alga em meio de cultura BSA (Batata-Sacarose-Ágar). No entanto, Ponmurugan et al. (2010) ao testarem diversos tipos de meios de cultura, obtiveram bons resultados com os meios sintéticos Trebouxia e Bristol, além da indução à germinação de zoósporos pelo emprego do hormônio ácido-3-indolacético (AIA) como componente de alguns dos meios de cultura avaliados.
O cultivo da alga em meio de cultura se faz importante para a caracterização micromorfológica de Cephaleuros sp., para se conhecer a fisiologia desse microorganismo e implicações sobre a epidemiologia da mancha de algas em campo (Vasconcelos et al. 2016a, Vasconcelos et al. 2017).

Este trabalho teve como objetivo avaliar o crescimento in vitro de Cephaleuros virescens (isolado $\mathrm{H}$ 27-01, proveniente de folhas lesionadas de Mangifera indica cv. Amrapali) em diferentes meios de cultura e sob o efeito de hormônios ácido-3-indolacético (AIA) e ácido-3-giberélico $\left(\mathrm{GA}_{3}\right)$.

\section{MATERIAL E MÉTODOS}

Para avaliar o crescimento in vitro de $C$. virescens, discos de ágar, contendo micélio do isolado $\mathrm{H}$ 27-01, proveniente de folhas de mangueira cv. Amrapali exibindo lesões da mancha de alga e pertencente à Coleção Micológica da Universidade Estadual de Goiás (UEG), Campus Ipameri, mantidos em meio básico de Bold (MBB) foram repicados para os meios: (a) meio básico de bold [MBB; contendo $\mathrm{g} \mathrm{L}^{-}$ ${ }^{1}$ : (1) $25 \mathrm{~g} \mathrm{NaNO}_{3}$, (2) $2,5 \mathrm{~g} \mathrm{CaCl}_{2} \cdot 2 \mathrm{H}_{2} \mathrm{O}$, (3) $7,5 \mathrm{~g}$ $\mathrm{MgSO}_{4} \cdot 7 \mathrm{H}_{2} \mathrm{O}$, (4) 7,5 g K $\mathrm{HPO}_{4}$, (5) $17,5 \mathrm{~g} \mathrm{KH}_{2} \mathrm{PO}_{4}$, (6) 2,5 g NaCl, (7) 50,0 g EDTA, (8) 31,0 g KOH, (9) 4,98 g FeSO $4.7 \mathrm{H}_{2} \mathrm{O}$, (10) 11,42 $\mathrm{g} \mathrm{H}_{3} \mathrm{BO}_{3}$, (11) $1 \mathrm{ml}$ $\mathrm{H}_{2} \mathrm{SO}_{4}$, (12) solução de micronutrientes contendo g $\mathrm{L}^{-1}$ : 8,82 g $\mathrm{ZnSO}_{4} .7 \mathrm{H}_{2} \mathrm{O}, 1,44$ g $\mathrm{MnCl}_{2} .4 \mathrm{H}_{2} \mathrm{O}, 0,71 \mathrm{~g}$ MoO3, 1,57 g CuSO $4.5 \mathrm{H}_{2} \mathrm{O}, 0,49$ g $\mathrm{Co}\left(\mathrm{NO}_{3}\right)^{2} .6 \mathrm{H}_{2} \mathrm{O}$; preparado com $10 \mathrm{~mL}$ das soluções $1-6,940 \mathrm{~mL}$ de água destilada, $1 \mathrm{~mL}$ das soluções 7-12 e 22g de ágar], (b) meio extrato da folha do hospedeiro agarizado (EFH; contendo: $1 \mathrm{~L}$ de filtrado a partir de $100 \mathrm{~g}$ de folhas de mangueira sadias trituradas, $20 \mathrm{~g}$ sacarose e $20 \mathrm{~g}$ ágar), (c) Meio Bristol [solução Bristol (contendo g $\mathrm{L}^{-1}$ : 0,097 $\mathrm{g} \mathrm{FeCl}_{2}$, 0,004 g MnCl$, 0,005 \mathrm{~g} \mathrm{ZnCl}_{2}, 0,002$ g $\mathrm{CaCl}_{2}$ e $\left.\left.0,004 \mathrm{~g} \mathrm{Na}_{2} \mathrm{MoO}_{4}\right)\right]$ e (d) meio Trebouxia (contendo $\mathrm{g} \mathrm{L}^{-1}: 10 \mathrm{~g}$ peptona proteose, $20 \mathrm{~g}$ glicose, 60 $\mathrm{mL}$ solução Bristol), totalizando 8 placas de Petri para cada meio de cultura.

A alga se manteve a $25^{\circ} \mathrm{C}$ e fotoperíodo de 12 $\mathrm{h}$, onde foram tomadas as medidas de diâmetro das colônias do $1^{\circ}$ ao $4^{\circ}$ dia em que, obtiveram-se os valores médios de duas medidas diametralmente opostas. Além disso, outros dois experimentos foram simultaneamente montados com os mesmos tratamentos descritos anteriormente, porém com a adição dos seguintes hormônios: (a) $150 \mathrm{mg} \mathrm{L}^{-1} \mathrm{de}$ ácido-3-indol acético (AIA) e (b) $150 \mathrm{mg} \mathrm{L}^{-1}$ de ácido3-giberélico $\left(\mathrm{GA}_{3}\right)$ e subsequente avaliação do crescimento micelial, conjuntamente aos tratamentos sem adição de hormônio. O delineamento experimental 
utilizado foi o de blocos casualizados (DBC), em esquema fatorial $4 \times 3$ (meios de cultura e hormônios), com oito repetições (oito placas de Perti para cada tratamento).

Os valores dos diâmetros das colônias $(\mathrm{cm})$ foram utilizados para se calcular a área ocupada pela colônia da alga do $1^{\circ}$ ao $4^{\circ}$ dia de crescimento, através da fórmula da circunferência (área ocupada pela colônia $\left.=\pi * r^{2}\right)$. Em seguida, para as análises estatísticas, foi considerada a área abaixo da curva de crescimento micelial (AACCM), a qual foi calculada a partir dos valores diários de área ocupada pela colônia $\left(\mathrm{cm}^{2}\right)$, através da fórmula AACCM $=\Sigma\left[((y 1+y 2) / 2)^{*}(t 2-t 1)\right]$, onde $y 1$ e $y 2$ são duas avaliações consecutivas realizadas nos tempos $t 1$ e $t 2$, respectivamente. Os valores de AACCM foram submetidos à análise de variância (ANOVA) e ao teste de Scott-Knott $(\mathrm{P} \leq 0,05)$, com auxílio do programa Sisvar 5.3 (Ferreira 2011).

\section{RESULTADOS E DISCUSSÃO}

$\mathrm{O}$ meio de cultura que proporcionou maior crescimento micelial médio de $C$. virescens foi o meio Trebouxia (AACCM $=73,68)$, independente do uso de hormônio (Tabela 1). Em seguida, o meio EFH proporcionou o segundo melhor crescimento médio $(29,93)$, exceto na ausência de hormônio $(22,75)$. O meio Bristol foi o que proporcionou o terceiro melhor crescimento médio $(27,56)$ da alga (média dos três tratamentos: sem hormônio, AIA e $\left.\mathrm{GA}_{3}\right)$. O meio MBB apresentou pior desempenho, consequentemente, proporcionando média estatisticamente inferior aos demais meios $(17,77)$.

Ao se comparar se a adição de hormônio interfere com o crescimento micelial de C. virescens, verificou-se que a ausência de hormônio, em média, proporcionou melhor crescimento micelial da alga $(42,41)$. O meio EFH foi a única exceção, exibindo aumento de AACCM quando da adição de hormônios. A adição de AIA ao meio de cultivo Trebouxia proporcionou maior valor de AACCM quando comparado à adição de $\mathrm{GA}_{3}$ no mesmo meio. Os demais meios foram indiferentes quanto ao tipo de hormônio utilizado. O meio Trebouxia foi o melhor para o crescimento da alga em todas as situações, proporcionando maiores valores de AACCM (Tabela 1), a qual foi calculada a partir dos valores diários de área ocupada pela colônia $\left(\mathrm{mm}^{2}\right)$ (Figuras 1,2 e 3).

Tabela 1. Área abaixo da curva de crescimento micelial (AACCM) de Cephaleuros virescens em diferentes meios de cultura, sem adição de hormônio e com adição de ácido-3-indolacético (AIA) e ácido-3-giberélico $\left(\mathrm{GA}_{3}\right)$. Ipameri, Goiás1.

\begin{tabular}{|c|c|c|c|c|}
\hline \multirow[t]{2}{*}{ Meio de cultura } & \multicolumn{3}{|c|}{ AACCM } & \multirow[b]{2}{*}{ Média } \\
\hline & $\begin{array}{c}\text { Sem } \\
\text { hormônio }\end{array}$ & AIA & $\mathrm{GA}_{3}$ & \\
\hline $\mathrm{MBB}$ & $26,39 \mathrm{cA}$ & $14,97 \mathrm{~dB}$ & $11,95 \mathrm{~dB}$ & $17,77 \mathrm{~d}$ \\
\hline EFH & $22,75 \mathrm{cB}$ & $34,68 \mathrm{bA}$ & $32,37 \mathrm{bA}$ & $29,93 \mathrm{~b}$ \\
\hline Bristol & $35,21 \mathrm{bA}$ & $22,61 \mathrm{cB}$ & $24,86 \mathrm{cB}$ & $27,56 \mathrm{c}$ \\
\hline Trebouxia & $85,29 \mathrm{aA}$ & $73,12 \mathrm{aB}$ & $62,63 \mathrm{aC}$ & $73,68 \mathrm{a}$ \\
\hline CV (\%) & 11,69 & 11,97 & 13,26 & 11,78 \\
\hline Média & $42,41 \mathrm{~A}$ & $36,35 \mathrm{~B}$ & $32,95 \mathrm{C}$ & - \\
\hline
\end{tabular}


REVISTA SCIENTIA AGRARIA

Versão On-line ISSN 1983-2443

Versão Impressa ISSN 1519-1125

SA vol. 19 n $^{\circ} .1$ Curitiba Jan/Mar 2018 p. 01-07

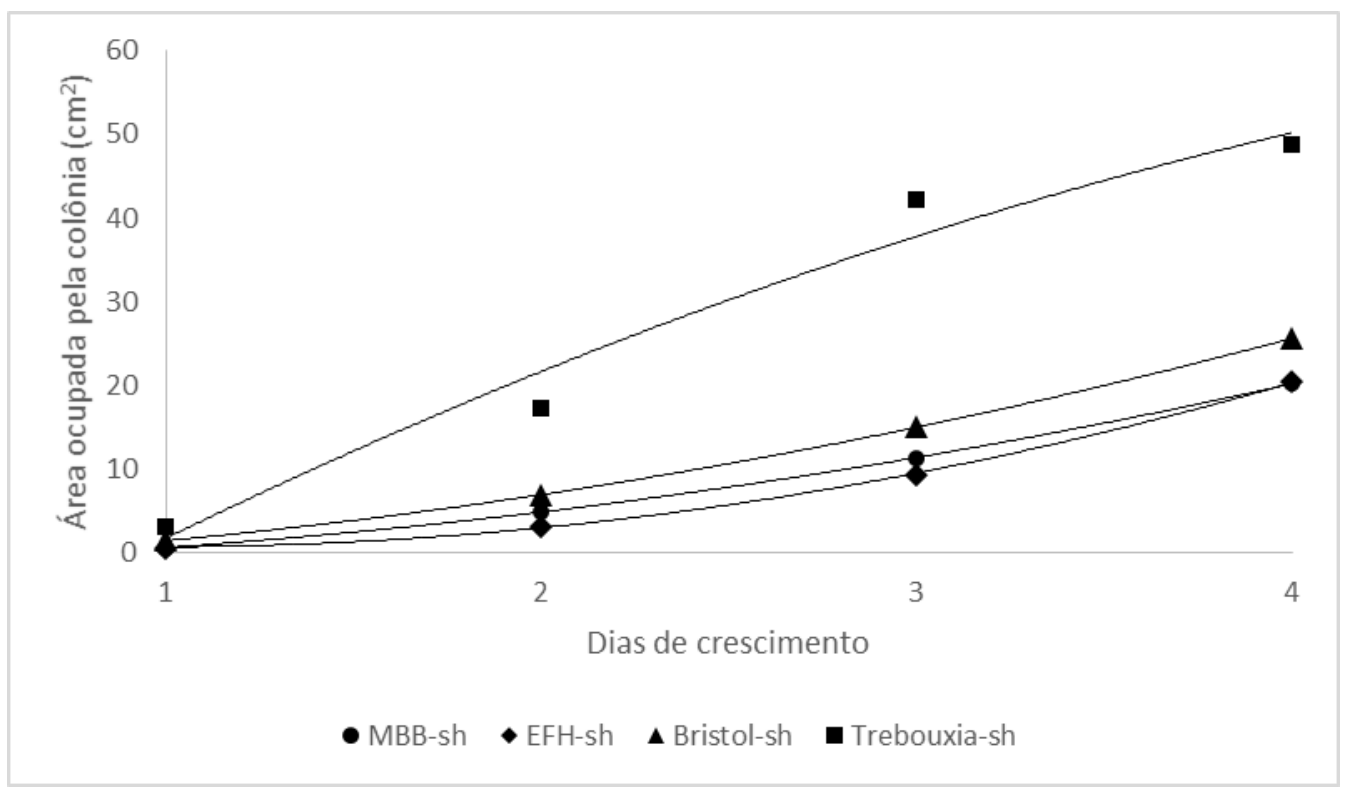

Figura 1. Área ocupada pela colônia $\left(\mathrm{cm}^{2}\right)$ de Cephaleuros virescens ao logo do tempo e em diferentes meios de cultura sem adição de hormônio (sh).

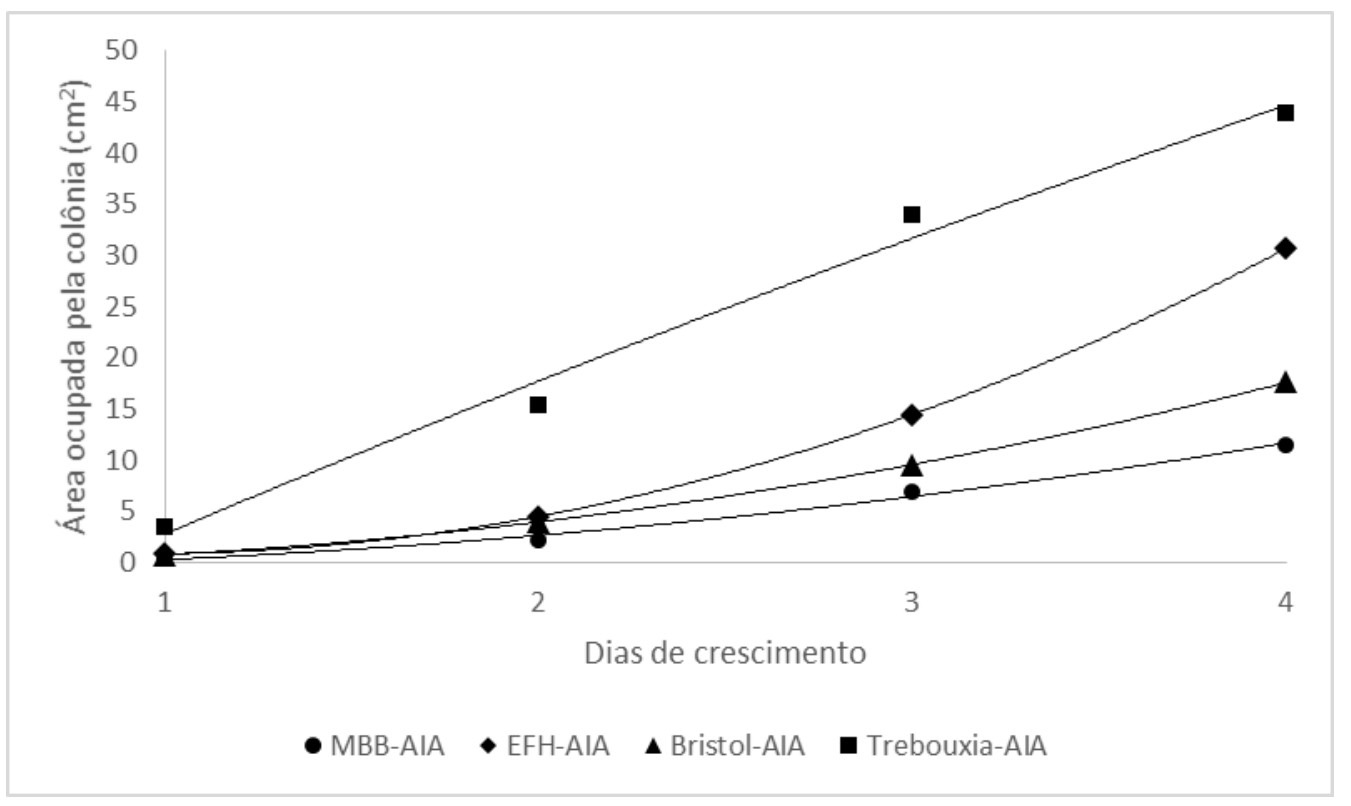

Figura 2. Área ocupada pela colônia $\left(\mathrm{cm}^{2}\right)$ de Cephaleuros virescens ao logo do tempo e em diferentes meios de cultura com adição de hormônio AIA a $150 \mathrm{mg} \mathrm{L}^{-1}$. 


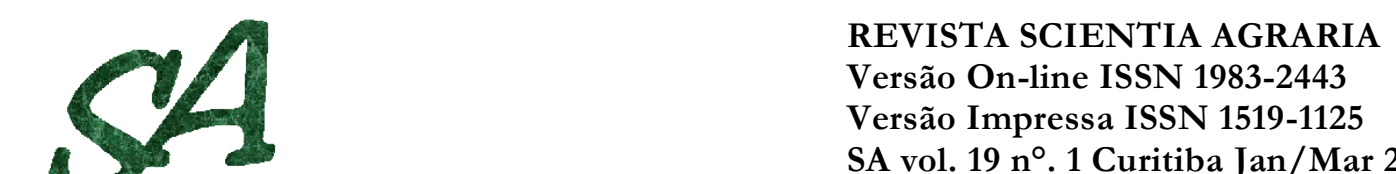

REVISTA SCIENTIA AGRARIA

Versão Impressa ISSN 1519-1125

SA vol. 19 n $^{\circ} .1$ Curitiba Jan/Mar 2018 p. 01-07

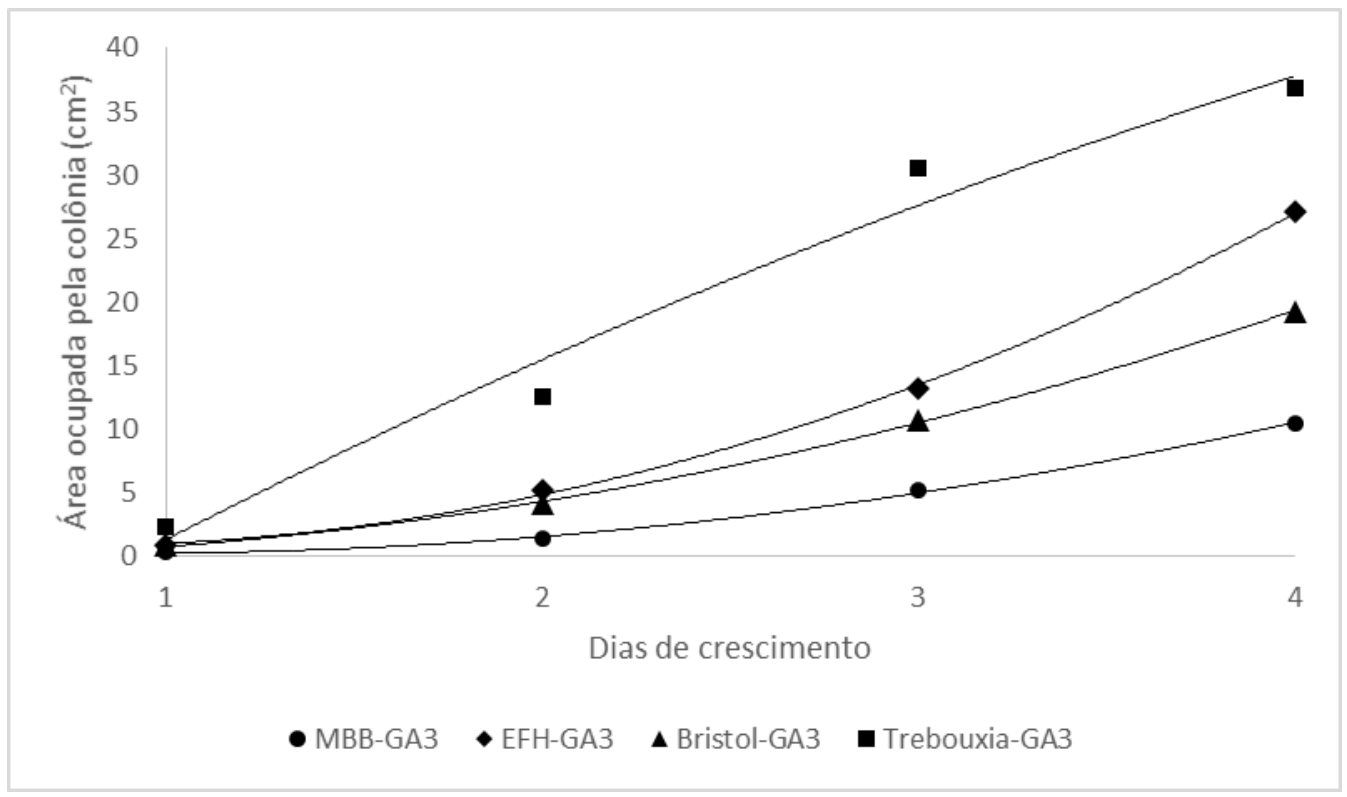

Figura 3. Área ocupada pela colônia $\left(\mathrm{cm}^{2}\right)$ de Cephaleuros virescens ao logo do tempo e em diferentes meios de cultura com adição de hormônio $\mathrm{GA}_{3}$ a $150 \mathrm{mg} \mathrm{L}^{-1}$.

O meio de cultura que proporcionou melhor crescimento micelial médio de $C$. virescens (AACCM) foi o meio Trebouxia, independente do uso de hormônio. Uma explicação para tal evento reside no fato de que este meio sintético é o meio mais completo dentre os meios avaliados, fornecendo nutrientes essenciais (fósforo, cálcio, magnésio, boro, cobre e zinco) para o desenvolvimento de microalgas e fontes orgânicas como nitrogênio e carbono (Ponmurugan et al. 2010). Um dos fatores que também pode estar relacionado a um maior crescimento da colônia é a composição do meio Trebouxia (peptona proteose, glicose e a solução Bristol em sua integralidade). De acordo com Vasconcelos et al. (2016 a), meios que apresentam fontes de nitrogênio, como a peptona, consideradas altamente energéticas, são mais apropriados para o crescimento das algas. Adicionalmente, Ren et al. (2013) preconizou que o meio Trebouxia fornece nitrogênio por meio da Peptona proteose, uma proteína semi-digerida que serve como fonte de nitrogênio, sendo este um nutriente essencial ao crescimento de algas. Em estudo recente, Ponmurugan et al. (2010) testaram diferentes meios de cultura, sintéticos e naturais, para o crescimento in vitro de $C$. parasiticus e, de forma análoga, obtiveram crescimento acentuado em meio Trebouxia. Um crescimento micelial rápido é importante, uma vez que reduz os riscos de contaminação na cultura pura do microrganismo (Jonathan et al. 2008, Sales Campos \& Andrade 2010).

$\mathrm{O}$ meios $\mathrm{EFH}$ e Bristol foram consideravelmente inferiores ao meio Trebouxia quanto ao crescimento médio (AACCM) in vitro, contrariando os resultados obtidos por Ponmurugan et al. (2010), em que os referidos meios de cultura haviam apresentado crescimento proeminente e similar. Entretanto, vale destacar que Ponmurugan et al. (2010), não obtiveram valores numéricos para o crescimento radial da alga, tampouco a conversão deste crescimento ao longo do tempo em AACCM. Ao contrário, estes autores aplicaram apenas uma escala de notas que classificava o crescimento de três isolados de $C$. parasiticus em: (1) proeminente, (2) moderado e (3) fraco. Neste sentido vale destacar a importância se integralizar a área abaixo da curva de crescimento micelial (AACCM), em estudos que envolvam a fisiologia, epidemiologia e o controle de fitopatógenos (Medeiros et al. 2006, Viana et al. 2008, Medeiros et al. 2012).

O MBB teve o pior desempenho em relação ao crescimento das colônias de C. virescens (Tabela 1). Embora contenha micronutrientes e macronutrientes, este é o meio mais sintético dentre os meios avaliados, possuindo 12 soluções diferentes em sua composição. Isso pode estar relacionado ao fato de que as algas se desenvolvem melhor em meios menos complexos e 
mais próximos de condições naturais onde elas se encontram, ou seja, eu meios não sintéticos (Jose \& Chowdary 1977). Pode-se inferir também ao fato de não se ter fornecido luminosidade constante no experimento, pois quando se mantém luminosidades constantes mais nutrientes são requeridos para suprir as necessidades fisiológicas de uma microalga e manter uma melhor eficiência fotossintética, gerando assim um maior crescimento da alga em condições in vitro (Perrine et al, 2012), isto é, possivelmente o maior potencial de crescimento da alga neste meio foi limitado pelas 12 horas de luz fornecida.

A ausência de hormônio, em média, proporcionou melhor crescimento micelial de $C$. virescens, exceto o meio EFH, o qual apresentou aumento de AACCM quando acrescido de AIA e $\mathrm{GA}_{3}$, comparado ao meio sem hormônio. Neste campo de pesquisa, ainda existem poucos estudos relacionados ao uso de hormônios para indução do crescimento e reprodução de algas. A maioria dos autores relaciona o papel dos hormônios à estimulação de formação de gametângio e de zoósporos e não ao crescimento micelial. Chowdary (1969) reportaram que esporângios e gametângios foram produzidos em $C$. virescens quando auxinas (ácido indolil-3-acético, indolil-3-butirico e ndolil-3-propionico) foram adicionadas ao meio de cultura.

\section{REFERÊNCIAS}

ANÚARIO BRASILEIRO DE FRUTICULTURA, Santa Cruz do Sul: Editora Gazeta, 2015, 104p.

CARVALHO, D. D. C.; OLIVEIRA, D. F.; PASQUAL, M. Aperfeiçoamento do teste com coleóptilo de trigo (Triticum aestivum L.) para a detecção de reguladores vegetais. Plant Cell Culture \& Micropropagation, v. 4, n. 1, p. 28-33, 2008.

CHOWDARY, Y. B. K. Induction of reproductive organs in Cephaleuros virescens. Indian Journal Microbiology, v. 3, p. 153-158, 1969.

FERREIRA, D. F. Sisvar: a computer statistical analysis system. Ciência e Agrotecnologia, v. 35, p. 10391042, 2011.

GOKHALE, M. V.; SHAIKH, S. S. Host range of a parasitic alga Cephaleuros virescens Kunz. Ex Fri. from Maharashtra state, India. Plant Sciences Feed. v. 12, p. 1-4, 2012.
Finalmente, ao se comparar os hormônios, a adição de AIA aos meios de cultivo proporcionou maior valor médio de AACCM. As alga C. virescens pertence ao mesmo reino que as plantas superiores e, embora comparações do efeito destes hormônios no crescimento de plantas não sejam apropriadas para a área da microbiologia, o que se pode inferir para explicar a diferença encontrada no crescimento de $C$. virescens, é que AIA e $\mathrm{GA}_{3}$ possuem mecanismos de ação distintos na promoção do crescimento in vitro de plantas, sendo que o AIA está relacionado ao alongamento e celular e o $\mathrm{GA}_{3}$ à divisão celular (Taiz \& Zeiger 2006, Carvalho et al. 2008). Neste sentido, ao se analisar o que fora pesquisado até o momento, o que se sabe é que em meio Trebouxia, a adição de AIA proporciona maior rapidez na germinação de zoósporo de C. paraisticus quando em comparação com o meio acrescido de $\mathrm{GA}_{3}$ (Ponmurugan et al. 2010).

\section{CONCLUSÕES}

Quando cultivada no meio Trebouxia, independente de uso de hormônios, obteve-se melhor crescimento in vitro de C. virescens. O meio EFH foi o único meio que apresentou aumento de AACCM quando adicionado por hormônios.

HAN, K. et al. First report of algal leaf spot associated with Cephaleuros virescens on greenhouse grown Ficus benghalensis in Korea. Australasian Plant Disease Notes, v. 6, p. $72-73,2011$.

HORTIFRUIT BRASIL. Retrospectiva 2015 \& Perspectiva
2016. $\quad$ Disponível em: http://www.hfbrasil.org.br/br/revista/acessar/capa/ahortifruit-brasil-vai-para-a-rede-em-2016. aspx. Acesso em: 13 de agosto de 2016.

JONATHAN, S. G. et al. Biodegradation of Nigerian wood wastes by Pleurotus tuber-regium (Fries) Singer. Bioresource Technology, v. 99, p. 807-811, 2008.

JOSE, G.; CHOWDARY, Y. B. K. Karyological studies on Cephaleuros Kunze. Acta Botanica Indica, v. 5, p. 114-122, 1977. 
MAIA, F. G. M. et al. Efeito da temperatura no crescimento micelial, produção e germinação de conídios de Colletotrichum spp. isolados de mangueira com sintomas de antracnose. Bioscience Journal, v. 27, n. 2, p. 205-210, 2011.

MALAGI, G. et al. Detecção de mancha-de-alga (Cephaleuros virescens Kunze) em citros no estado do Paraná. Revista Brasileira de Agrociência, v. 17, p. 148-152, 2011.

MEDEIROS, E. V.; JÚNIOR, R. S.; MICHEREFF, S. J. Eficiência de fungicidas no controle "in vitro" de Monosporascus cannonballus. Revista Caatinga, v. 19, n. 4, p. 360-368, 2006.

MEDEIROS, E. V.; VIANA, M. G.; ALBUQUERQUE, C. C. Extrato etanólico de Senna alata no controle de Fusarium oxysporum, causador da murcha-de-fusarium do meloeiro. Revista Brasileira de Engenharia Agricola e Ambiental, v. 16, n. 11, p. 11661170, 2012.

NELSON, S. Cephaleuros Species, the plant-parasitic Green algae. Plant Disease, v. 43, p. 1-6, 2008.

PERRINE, Z.; NEGI, S.; SAYRE, R.T. Optimization of photosynthetic light energy utilization by microalgae. Algal Research, v.1, n. 2, p. 134-142, 2012.

POLTRONIERIL, T. et al. Alga causando necrose foliar em helicônia no Pará. Summa Phytopathologica, v. 39, p. 139-139, 2013.

PONMURUGAN, P. et al. Studies on Cephaleuros parasiticus Karst, a pathogenic alga causing red rust disease in tea plantations. Journal of Plantation Crops, v. 37, p. 70-73, 2009.

PONMURUGAN, P.; SARAVANAM, D.; RAMYA, M. Culture and biochemical analysis of a tea algal pathogen, Cephaleuros parasiticus. Journal of Phycology, v. 46, p. 1017-1023, 2010.
REN, H. et al. A new lipid-rich microalga Scenedesmus sp. strain R-16 isolated using Nile red staining: effects of carbon and nitrogen sources and initial $\mathrm{pH}$ on the biomass and lipid production. Biotechnology for Biofuels, v. 6, p. 143, 2013.

SALES JÚNIOR, R. et al. The use of azoxystrobin in the control of mango anthracnosis. Fitopatologia Brasileira, v. 29, n. 2, p. 193-196, 2004.

SUNPAPAO, A.; PITALOKA, M. K. A new record of plant parasitic green algae, Cephaleuros diffusus (Trentepohliaceae, Chlorophyta), on Acacia auriculiformis hosts in Thailand. Biodiversitas, v. 16, n. 2, p. 116-120, 2015.

SUTO, Y.; OHTANI. S. Morphological features and chromosome numbers in cultures of five Cephaleuros species (Trentepohliaceae, Chlorophyta) from Japan. Phycological Research, v. 59, p. 42-51, 2011.

TAIZ, L.; ZEIGER, E. Plant physiology. 4. ed. Sunderland: Sinauer, 2006. $764 \mathrm{p}$

VASCONCELOS, C. V.; PEREIRA, F. T.; CARVALHO, D. D. C. Aspectos relevantes para o conhecimento de Cephaleuros sp.: morfologia, fisiologia e ecologia. Scientia Agraria Paranaensis, v. 15, n. 3, p. 228-235, 2016 a.

VASCONCELOS, C.V. et al. Occurrence of algal leaf spot (Cephaleuros virescens Kunze) on avocado in Goiás State, Brazil. Summa Phytopathologica, v. 41, n. 1, p. 108, 2016 b.

VASCONCELOS, C.V. et al. Ocorrência da mancha de algas em mangueira cv. 'Amrapali' em Ipameri, Goiás. Agropecuária Científica no Semi-Árido, v.13, n.1, p.5-8, 2017.

VIANA, M.G. et al. Avaliação do potencial fungicida de extratos etanólicos de Senna alata contra Monosparacus cannonballus. Ciên 